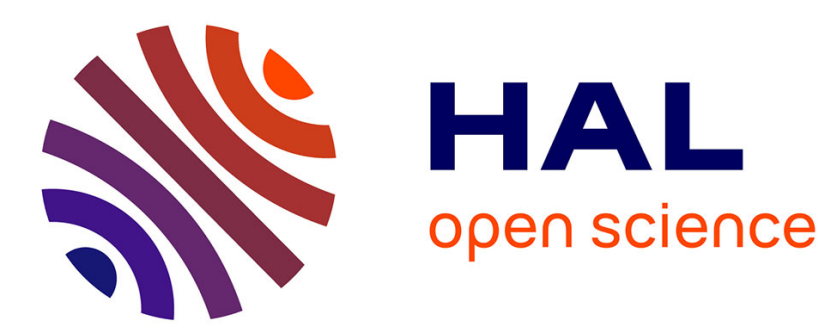

\title{
Large scale Tesla coil guided discharges initiated by femtosecond laser filamentation in air
}

Léonid Arantchouk, Guillaume Point, Yohann Brelet, Bernard Prade, Jérôme Carbonnel, Yves-Bernard André, André Mysyrowicz, Aurélien Houard

\section{- To cite this version:}

Léonid Arantchouk, Guillaume Point, Yohann Brelet, Bernard Prade, Jérôme Carbonnel, et al.. Large scale Tesla coil guided discharges initiated by femtosecond laser filamentation in air. Journal of Applied Physics, 2014, 116, pp.13303. 10.1063/1.4886582 . hal-01118217

\section{HAL Id: hal-01118217 \\ https://hal-ensta-paris.archives-ouvertes.fr/hal-01118217}

Submitted on 18 Feb 2015

HAL is a multi-disciplinary open access archive for the deposit and dissemination of scientific research documents, whether they are published or not. The documents may come from teaching and research institutions in France or abroad, or from public or private research centers.
L'archive ouverte pluridisciplinaire HAL, est destinée au dépôt et à la diffusion de documents scientifiques de niveau recherche, publiés ou non, émanant des établissements d'enseignement et de recherche français ou étrangers, des laboratoires publics ou privés. 


\title{
Large scale Tesla coil guided discharges initiated by femtosecond laser filamentation in air
}

\author{
L. Arantchouk ${ }^{1}$, G. Point ${ }^{2}$, Y. Brelet ${ }^{2}$, B. Prade $^{2}$, J. Carbonnel $^{2}$, \\ Y.-B. André2 ${ }^{2}$ A. Mysyrowicz ${ }^{2}$, A. Houard ${ }^{2, a)}$ \\ ${ }^{1}$ Laboratoire de Physique des Plasmas - Ecole Polytechnique, CNRS - 91128 Palaiseau, France \\ ${ }^{2}$ Laboratoire d'Optique Appliquée - ENSTA ParisTech, Ecole Polytechnique, CNRS - 91761 Palaiseau, \\ France
}

\begin{abstract}
The guiding of meter scale electric discharges produced in air by a Tesla coil is realized in laboratory using a focused terawatt laser pulse undergoing filamentation. The influence of the focus position, the laser arrival time or the gap length is studied to determine the best conditions for efficient laser guiding. Discharge parameters such as delay, jitter and resistance are characterized. An increase of the discharge length by a factor 5 has been achieved with the laser filaments, corresponding to a mean breakdown field of $2 \mathrm{kV} / \mathrm{cm}$ for a $1.8 \mathrm{~m}$ gap length. Consecutive guided discharges at a repetition rate of $10 \mathrm{~Hz}$ are also reported.
\end{abstract}

\section{INTRODUCTION}

Intense ultrashort laser pulses propagating through atmosphere give rise to spectacular non-linear effects. Owing to a dynamic competition between non-linear optical Kerr self-focusing, diffraction, multiphoton absorption and plasma induced defocusing, a contracted beam of high peak intensity can be formed over long distances. This intense laser pulse leaves in its wake a long and thin column of weakly ionized plasma. This process is usually referred to as filamentation [1-4]. Plasma filaments are useful for remote manipulation of high voltage (HV) discharges. They can trigger and guide MV discharges over several meters [5-6], carry high DC currents with reduced losses [7] or deviate arcs from their natural path [8]. These properties are of great interest for applications such as the laser lightning rod [9-10], virtual plasma antennas for radiofrequency (RF) transmission [11-12], plasma aerodynamic control [13-14], high voltage switch with low jitter [15-16], or compact Marx generator [17].

Experiment on triggering and guiding of large scale $(0.5-3 \mathrm{~m})$ discharges by use of laser-induced ionized filament have been performed so far with monopolar pulsed or DC high voltage sources, where the electric field direction remains constant, typically with Marx generators [18-19], or Van de Graaf machines [20]. It has been shown that the presence of the plasma filament can decrease the breakdown voltage by $30 \%$ to $50 \%$ depending on the voltage polarity for a $2.5 \mathrm{~m}$ spark with a Marx generator [8].

Recently, demonstration of discharge triggering and guiding by femtosecond laser filaments using a Tesla coil generator has been reported by two groups revealing a large reduction of the AC breakdown field with the filaments [21-23]. In this manuscript we study in detail the influence of the different experimental parameters on the guiding efficiency and on the spark parameters. We observe that the guiding effect strongly depends on the amplitude and polarity of the Tesla field when the filament is formed between the electrodes.

\section{METHODS}

\section{A. Experimental setup}

The ENSTAmobile laser was used to create the plasma filaments in air. This Chirped Pulse Amplified (CPA) laser chain can deliver $50 \mathrm{fs}$ pulses with energy of $300 \mathrm{~mJ}$ at a maximum repetition rate of $10 \mathrm{~Hz}$. For the present experiment, the $50 \mathrm{fs}$ pulses were chirped to $700 \mathrm{fs}$. The laser beam was focused in air by a $5 \mathrm{~m}$ converging lens, generating a bundle of multifilaments extending $200 \mathrm{~cm}$ before and $50 \mathrm{~cm}$ after the geometrical focus of the lens. A detailed analysis of the generated filaments can be found in ref [24]. Two brass spherical electrodes $(\varnothing 10 \mathrm{~mm})$, one linked to the Tesla coil, the other to the ground, are used to create the discharge. They were aligned with the laser beam so that filaments skimmed both of them. In usual experimental geometry the laser beam met the HV electrode first.

\section{B. Description of the Tesla coil}

\footnotetext{
a) Author to whom correspondence should be addressed. Electronic mail: aurelien.houard@ensta.fr.
} 
The Tesla resonant transformer consists of two magnetically coupled LC circuits with close resonant frequencies $\Omega_{0}=\left(\mathrm{L}_{1} \mathrm{C}_{1}\right)^{1 / 2}=\left(\mathrm{L}_{2} \mathrm{C}_{2}\right)^{1 / 2} \approx 100 \mathrm{kHz}$ (cf. Figure 1). The primary capacitor $\mathrm{C}_{1}$ is made of twenty parallel ceramic disc capacitors $\left(2 \mathrm{nF}\right.$ each, i. e. $\left.\mathrm{C}_{1}=40 \mathrm{nF}\right)$. The operation of the generator is governed by a trigatron allowing synchronization of the HV source with the laser with a temporal jitter $<20 \mathrm{~ns}$. The triggering of $\mathrm{C}_{1}$ charged up to 8-14 kV generates a magnetic field in $\mathrm{L}_{1}$, which is coupled via mutual inductance with $\mathrm{L}_{2}$. The secondary coil has a diameter of $20 \mathrm{~cm}$ and a length of $100 \mathrm{~cm}$ with $\mathrm{N}=1150$ turns, which yields $\mathrm{L}_{2}=52.9$ $\mathrm{mH}$. The output distributed capacitor $\mathrm{C}_{2}$ is composed of two parts, neglecting the capacitance arising from room environment. The first one is the self-capacitance of the coil $(\sim 15.3 \mathrm{pF})$ [25] and the second one is the toroidalshape termination of the Tesla with an outer diameter of $80 \mathrm{~cm}$ and a cross section diameter of $16 \mathrm{~cm}$, resulting in $33.6 \mathrm{pF}$. The total capacitance $\mathrm{C}_{2}$ is then estimated to be about $49 \mathrm{pF}$. This value was found to be in good agreement with the resonance frequencies of the Tesla coil.

The voltage $\mathrm{V}_{2}$ at the output of the Tesla secondary circuit is a superposition of two damped sinusoidal oscillations of frequencies $\omega_{1,2}=0.5\left(\omega_{+} \pm \omega_{-}\right)$, with $\omega_{+/-}=\Omega_{0}(1 \pm k)^{-1 / 2}$, where $k$ is the effective coupling coefficient between primary and secondary coil inductances $\mathrm{L}_{1}$ and $\mathrm{L}_{2}$. It results in the generation of an oscillating high electric potential also referred as a beat structure (Figure 2(a)). The experiments are carried out with a fairly small $\mathrm{HV}$ source delivering up to $\mathrm{V}_{1}=12.5 \mathrm{kV}$ to the primary Tesla capacitor $\mathrm{C}_{1}$ which thus stores an energy $\mathrm{E}_{\mathrm{C} 1} \approx 3 \mathrm{~J}$. The maximal absolute amplitude of $\mathrm{V}_{2}$ reaches $365 \mathrm{kV}$.
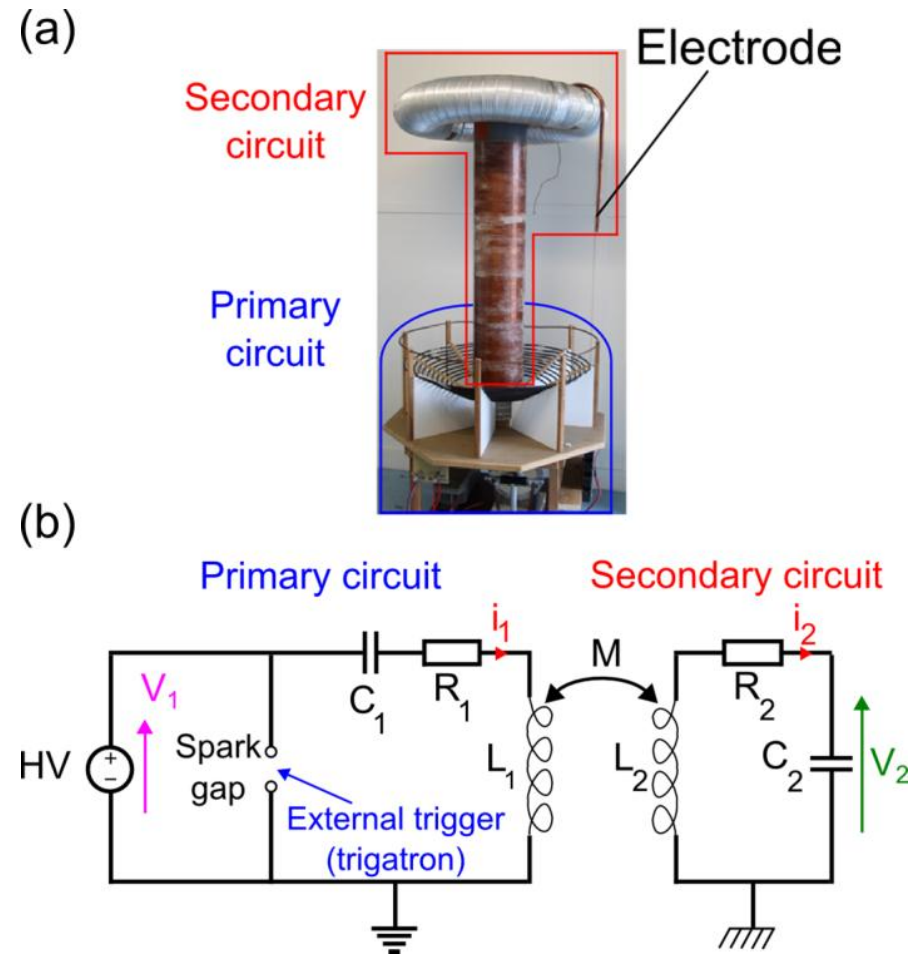

FIG. 1. (a) Photograph of the Tesla coil used in the experiments. (b) Equivalent electric schema.

\section{Diagnostics}

Voltage on the primary capacitor $\mathrm{C}_{1}$ was measured by a high voltage probe (PVM-1 from North Star with an $80 \mathrm{MHz}$ bandwidth). The discharge current at the output Tesla generator was monitored with a current viewing resistor installed in the ground electrode. The Tesla coil output voltage was probed by a remote antenna. This antenna, a $70 \mathrm{~mm}$-wide copper disk, was directed towards the output torus of the Tesla coil, and connected to a 1-M $\Omega$ oscilloscope channel using a $12.5 \mathrm{~m}$ coaxial cable, thus forming a capacitive divider. The HV part of this divider consists of the very small capacitor between the disk and the Tesla coil. Its low voltage part lies in the cable capacitance $\mathrm{C}_{\text {cable }}=0.1 \mathrm{nF} \cdot \mathrm{m}^{-1} \times 12.5 \mathrm{~m}=1.25 \mathrm{nF}$. This approximation is valid for a time scale $\tau \ll 1.25 \mathrm{nF} \times 1 \mathrm{M} \Omega=1.25 \mathrm{~ms}$, and can then be applied for the monitoring of the $100 \mathrm{kHz}$ oscillation of the generator. The signal generated by the antenna, placed at $2.5 \mathrm{~m}$ from the Tesla coil, is displayed in Figure 2(a).

The calibration of the antenna was done using a resistive divider made of twenty $18-\mathrm{k} \Omega$ high voltage resistances and by varying the supply voltage from 3 to $6 \mathrm{kV}$ on the primary Tesla capacitor $\mathrm{C}_{1}$. The influence of the resistive probe on Tesla characteristics was controlled by the antenna. Despite the fact that the total 
resistance of the probe $\left(360 \mathrm{k} \Omega\right.$ ) was well above the Tesla output impedance $\mathrm{Z}_{2} \approx\left(\mathrm{L}_{2} / \mathrm{C}_{2}\right)^{1 / 2}=33 \mathrm{k} \Omega$, the antenna signal shows about $30 \%$ drop when the probe is connected to the Tesla coil. With this correction we estimate the Tesla transformer gain $\mathrm{G}$ to $28.9 \pm 1$. This gain is very close to the theoretical value $\mathrm{G}_{\text {calc }}=$ $\left(\mathrm{C}_{1} / \mathrm{C}_{2}\right)^{1 / 2}=28$. Using this diagnostic, we estimate the precision of voltage measurements to be better than $7 \%$.

The experiments presented in this paper deal with the first half of the first beat period, and were done using an input voltage $\mathrm{V}_{1}=12.5 \mathrm{kV}$ DC, yielding a maximum output voltage amplitude of $365 \mathrm{kV}$. The period of the high-frequency oscillation $\mathrm{T}$ is $9.66 \mu \mathrm{s}$. The antenna allows us not only to monitor the output Tesla voltage during experiments but also to indicate the moment of laser beam arrival into the inter electrode gap, as evidenced by the appearance of a noisy spike on the signal at this moment (cf. Figure 2(b)). The occurrence of breakdown is also clearly visible on the antenna signal in the shape of exponentially damped high-frequency oscillations (Figure 2(b)).
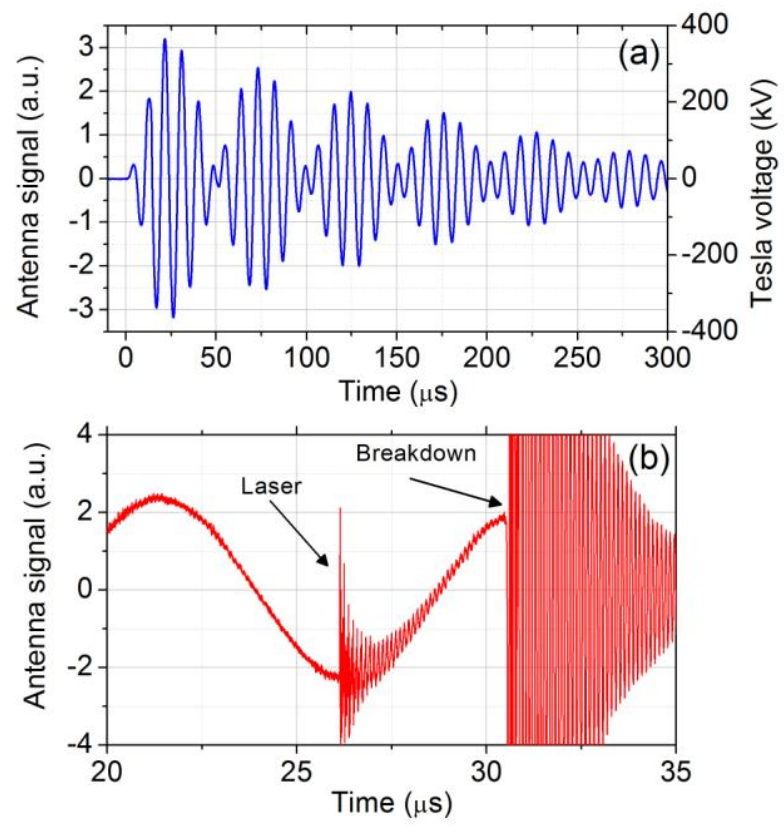

FIG. 2. (a) Antenna signal generated by the Tesla coil in absence of discharge. (b) Antenna signal in the presence of a laser induced discharge.

\section{RESULTS}

\section{A. Guided electric discharges}

We first measured the self-breakdown voltage of the Tesla generator with our electrode configuration in absence of laser filaments. We determined that for voltage maximal amplitude of $365 \mathrm{kV}$ the maximum inter-electrode spacing for which self-breakdown can occur was $\mathrm{L}_{\max } \sim 32 \mathrm{~cm}$. This corresponds to an effective electric field $\mathrm{E}_{\mathrm{eff}}=\mathrm{V}_{2, \max } / \mathrm{L}_{\max } \sim 11.4 \mathrm{kV} / \mathrm{cm}$.

The guiding effect of the filaments was characterized by means of time-integrated pictures of the discharges using a standard commercial camera (Canon EOS $650 \mathrm{D}$ fitted with a 18-135 mm f/3.5-5.6 objective). Examples of such pictures are displayed in Figure 3 in the case of $32 \mathrm{~cm}$-long discharges without (a) and with the presence of laser filaments in the gap (b). In the case of short gaps, close to the self-breakdown limit $(40-50 \mathrm{~cm})$, the inter-electrode electric field is high enough so that the guiding effect of the filaments is marginal. In this case, the path generated by the laser has to compete with naturally occurring streamers able to fill a large portion of the gap, often resulting in a partially-guided discharge, as seen on Figure 3(c) for a $40 \mathrm{~cm}$ gap. To ensure full guiding for such short gaps, the laser has to be sent before the inception of streamers [8]. In the case of longer gaps, as the electric field is less important, the guiding effect of the filaments dramatically improves. 

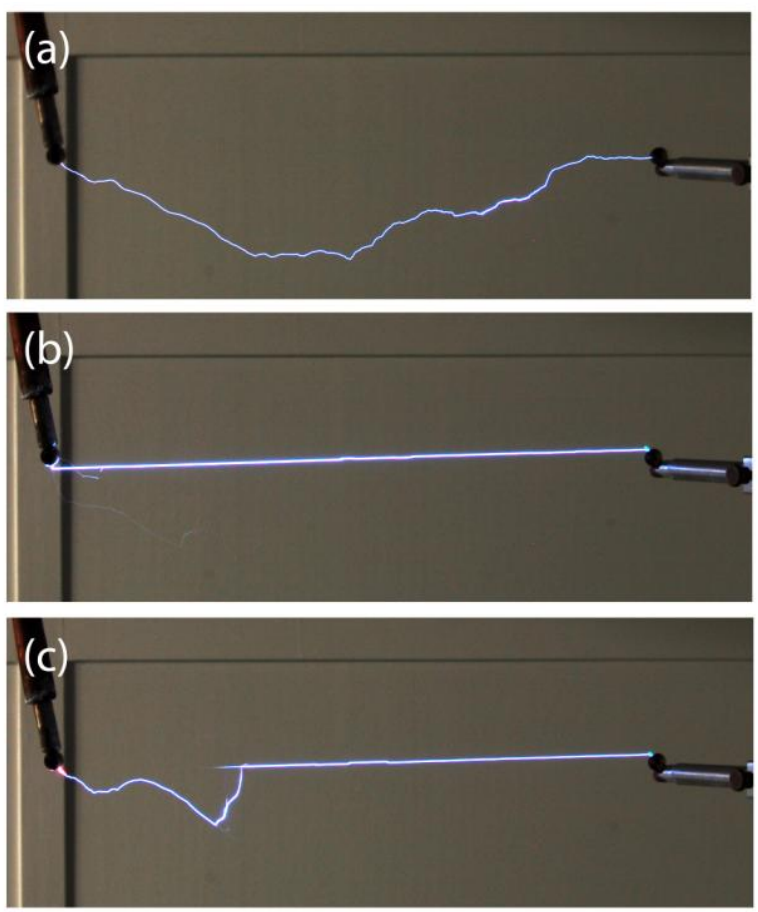

FIG. 3. Time-integrated images of spark discharges: without any apparent guiding (a), fully guided (b) and partially guided by the laser filament (c). The laser pulse comes from the left and the gap length is fixed to 32 $\mathrm{cm}$.

\section{B. Influence of the position of the laser geometrical focus}

First, we studied the influence of the laser beam focus position on the laser-induced breakdown probability. Five focal positions in the discharge gap were tested: on the first electrode (P1), $10 \mathrm{~cm}$ after this electrode (P2), in the middle of the gap (P3), $10 \mathrm{~cm}$ before the second electrode (P4) and finally on the furthermost electrode (P5). For a given focus position, we varied the laser arrival time $t_{\text {laser }}$ with respect to the Tesla triggering time, taken as $t=$ 0 . We used a $1 \mu$ s time step, ranging from $t_{\text {laser }}=7.1 \mu$ s (Tesla voltage first negative peak) to $t_{\text {laser }}=26.4 \mu \mathrm{s}$ (voltage maximum negative peak). This time window is indeed considered as most favorable for breakdown because it is characterized by a rising amplitude for voltage peaks.

For the gap $\mathrm{L}=50 \mathrm{~cm}$, all tested focus positions gave breakdown probability of $100 \%$ at the negative peak $26.4 \mu \mathrm{s}$ and positive peak $21.6 \mu \mathrm{s}$. With longer gaps $(80<\mathrm{L}<140 \mathrm{~cm})$, the highest breakdown probabilities were obtained when the linear focus was positioned near the second electrode. To trigger the longest gap $(\mathrm{L}=180 \mathrm{~cm})$ we had to adjust the focus point $30 \mathrm{~cm}$ before the second electrode.

These results can be explained by the spatial structure of the multifilament bundle. Using impacts on photographic plates, we were able to determine that most of the filaments appear before the lens geometrical focus, and quickly disappear beyond this point. The focus position therefore needs to be carefully adapted to each experimental setup. All the results presented in this paper were obtained by focusing the laser beam on the grounded electrode, which proved to be the most adapted configuration for the studied gaps.

\section{Influence of the laser arrival time}

The next parameter under investigation is the breakdown probability $\mathrm{P}$ as a function of the laser arrival moment $t_{\text {laser }}$ and the gap length $L$. For a given $L$ value, we again varied $t_{\text {laser }}$ with a $1 \mu$ s time step between $t=7 \mu \mathrm{s}$ and $t$ $=28 \mu \mathrm{s}$. Statistics are based on 10-20 shots. Two geometries were tested. In the configuration 1 the laser met the HV Tesla electrode first, then the grounded electrode. In the configuration 2, we inverted the two electrodes. Some of the data are depicted in Figure 4. For convenience, the temporal evolution of the Tesla voltage in absence of discharge is plotted on the same graphs (continuous line). 
(a)
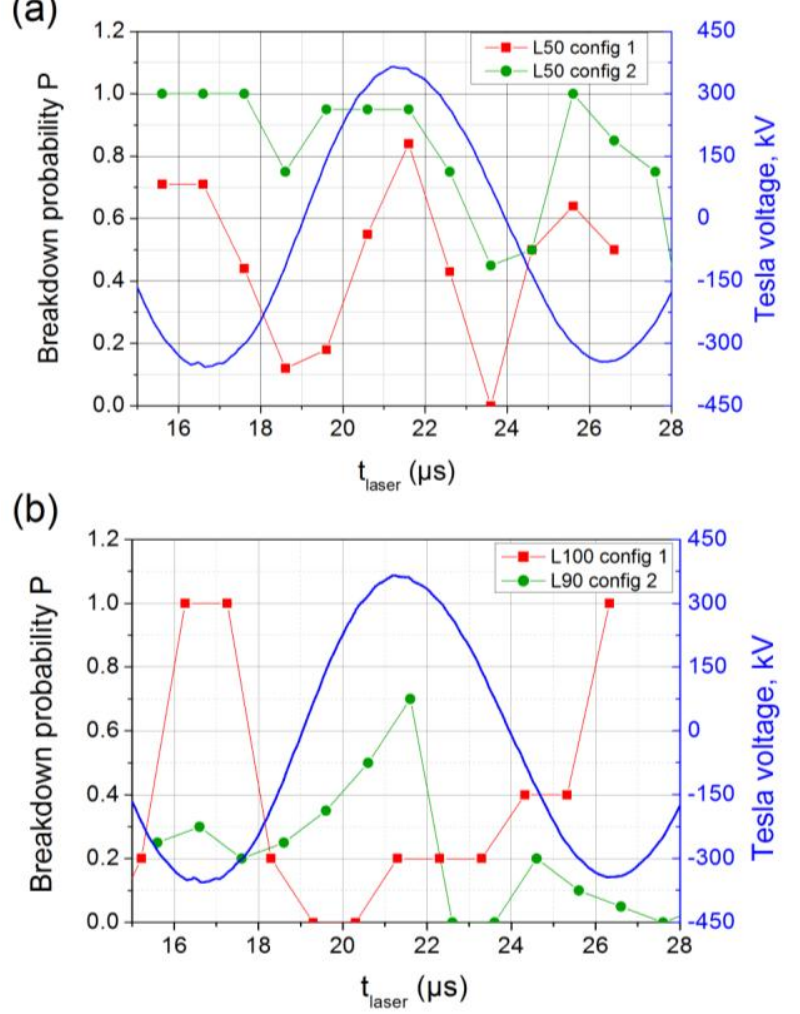

FIG. 4. Evolution of the breakdown probability $\mathrm{P}$ with $\mathrm{t}_{\text {laser }}$. (a): $\mathrm{L}=50 \mathrm{~cm}$, configuration 1 (red solid curve and squares) and configuration 2 (green solid curve and circles). (b) $\mathrm{L}=100 \mathrm{~cm}$, configuration 1 (red solid curve and squares) and $\mathrm{L}=90 \mathrm{~cm}$, configuration 2 (green solid curve and circles).

First, we can see that the breakdown probability is maximum when the laser arrives close to a voltage extremum, and is low when filaments are created while the voltage is close to zero. For long gaps $(\mathrm{L}>70 \mathrm{~cm})$, voltage polarity is also an important parameter, since in configuration $1, \mathrm{P}$ is maximal nearby negative voltage extrema and lower around positive voltage peaks. Opposite results arise in the inverted configuration. This polarity selectivity is less pronounced for short gaps, for which P remains high overall (Figure 4(a)). When the laser arrives early with respect to the Tesla oscillations ( $\mathrm{t}_{\text {laser }}<15 \mu \mathrm{s}$ ), $\mathrm{P}$ is almost constant, losing all selectivity in time.

For very long gaps $(\mathrm{L}>140 \mathrm{~cm})$, the best results were obtained when the laser was sent on the first Tesla voltage peaks $\left(\mathrm{t}_{\text {laser }}=7.1,11.9\right.$ and $\left.16.7 \mu \mathrm{s}\right)$ in configuration 1 . We thus achieved $\mathrm{P}=0.5$ for $\mathrm{L}=140 \mathrm{~cm}$, and $\mathrm{P}$ $=0.06$ for our limit gap $\mathrm{L}=180 \mathrm{~cm}$, corresponding to an average electric field of respectively 2.6 and $2 \mathrm{kV} / \mathrm{cm}$.

Note that electrode configuration 1 was kept for the rest of the experiments presented in this paper.

\section{Breakdown delay}

The breakdown delay $\Delta \mathrm{t}$ is defined as the time interval between the arrival of the laser pulse in the gap and the breakdown occurrence: $\Delta \mathrm{t}=\mathrm{t}_{\mathrm{bd}}-\mathrm{t}_{\text {laser }}$. The influence of $\mathrm{L}$ and $\mathrm{t}_{\text {laser }}$ on this parameter gives insight about the discharge development. Figure 5 presents the evolution of $\Delta \mathrm{t}$ with $\mathrm{t}_{\text {laser }}$ for the two previously studied gap lengths $(\mathrm{L}=50$ and $100 \mathrm{~cm})$. In the same figure are represented the positions of the Tesla voltage extrema. One can first see that breakdown events are distributed along these lines. A more careful look shows that most breakdowns take place slightly before the voltage reaches its local extremum, up to $600 \mathrm{~ns}$ before.

For $\mathrm{L}=50 \mathrm{~cm}$, at a given $\mathrm{t}_{\text {laser }}$, breakdown events are mainly scattered in three groups, which are located around the three voltage extrema following the laser arrival. Occurrences are relatively well balanced between these groups, proving again that polarity dependence is very weak for short gaps. The delay $\Delta t$ can be as short as $200 \mathrm{~ns}$. For $\mathrm{L}=100 \mathrm{~cm}$, the three groups previously seen are reduced to one large group. Most notably, this unique ensemble is located close to the position of a negative voltage maximum, and corresponds to a delay $\Delta \mathrm{t}$ of at least a full period of the Tesla voltage, $\mathrm{T}$. 

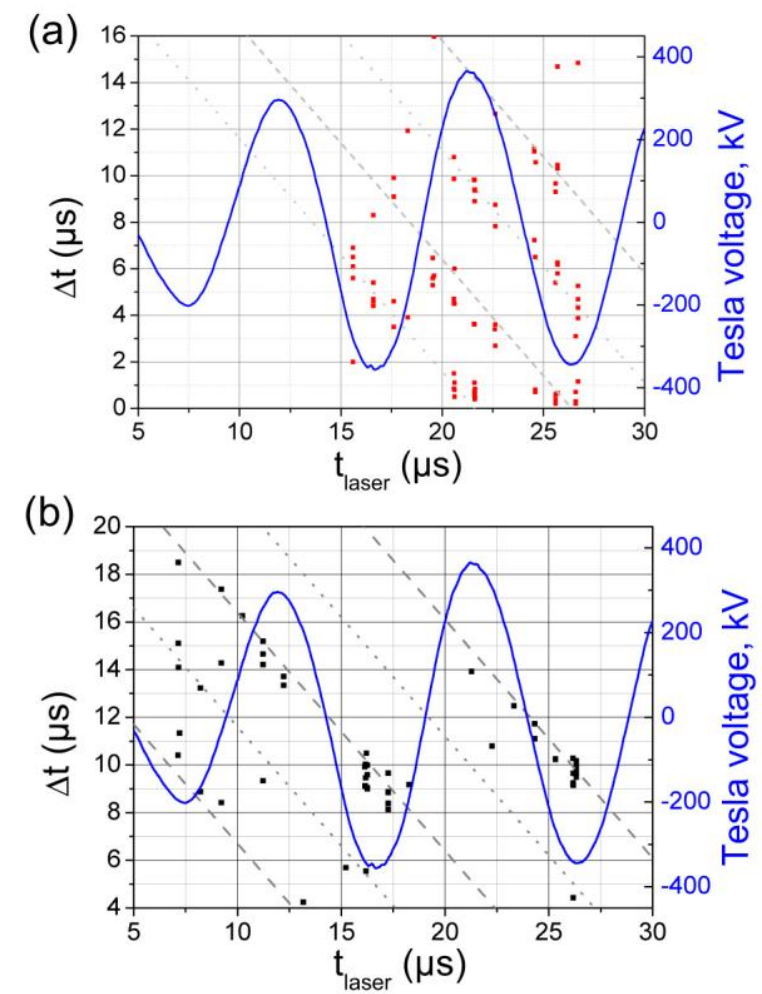

FIG. 5. $\Delta \mathrm{t}$ as a function of $\mathrm{t}_{\text {laser }}$ for $\mathrm{L}=50 \mathrm{~cm}$ (a) and $\mathrm{L}=100 \mathrm{~cm}$ (b) (scatter plots). The oblique lines represent the time position of positive (dotted lines) and negative (dashed lines) Tesla voltage peaks. The evolution of the

Tesla voltage (blue solid line) in time is also given for convenience.

Moreover, the longer the gap, the more the time needed for the spark to develop. For very long gaps (L > $140 \mathrm{~cm}), \Delta \mathrm{t}$ can be as high as $2 \mathrm{~T}$, that is the discharge takes as long as $20 \mu$ s to occur. This explains why the laser should be sent at early times to have the highest probability in this case.

Note that for selected parameters, very reproducible discharge can be obtained. Using a delay of $16.7 \mu \mathrm{s}$ and gap length $\mathrm{L}=100 \mathrm{~cm}$, we were able to generate repetitive guided discharges at $10 \mathrm{~Hz}$ during several seconds with a $100 \%$ probability.

\section{E. Discharge current and spark resistance}

We now study the voltage-current characteristics of the laser-triggered discharges. Typical current signals for L $=50 \mathrm{~cm}$ and $\mathrm{L}=100 \mathrm{~cm}$ are presented in Figure 6 . These curves present a main peak close to Gaussian, followed by strongly damped oscillations. Current amplitude is on the order of a few hundred amperes, and current duration is less than $100 \mathrm{~ns}$. With longer gaps the main current peak tends to decrease in amplitude and to widen.

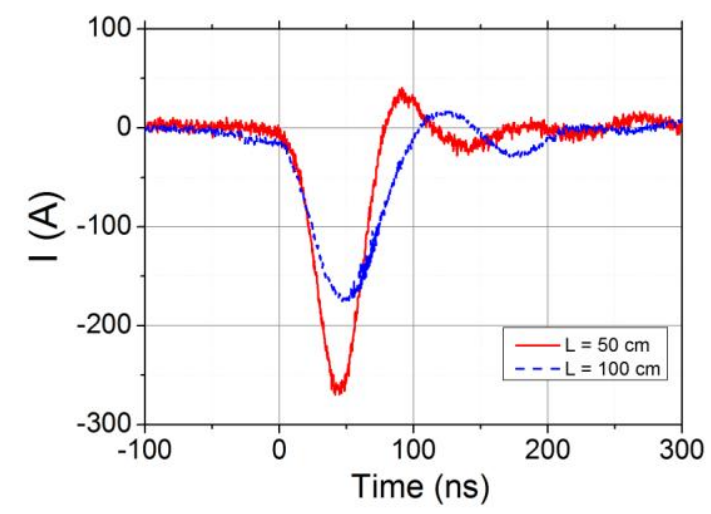

FIG. 6. Typical discharge current curves for $\mathrm{L}=50 \mathrm{~cm}$ (red solid line) and $\mathrm{L}=100 \mathrm{~cm}$ (blue dashed line). 
As seen in Figure 2, our voltage diagnostic does not allow monitoring the voltage evolution after the breakdown due to an important electromagnetic noise. To characterize the discharge resistivity we then choose to define an operational discharge resistance $\mathrm{R}=\mathrm{U}_{\mathrm{bd}} / \mathrm{I}_{\max }$, where $\mathrm{U}_{\mathrm{bd}}$ is the Tesla voltage at the breakdown time $\mathrm{t}_{\mathrm{bd}}$ and $\mathrm{I}_{\max }$ is the discharge current amplitude.
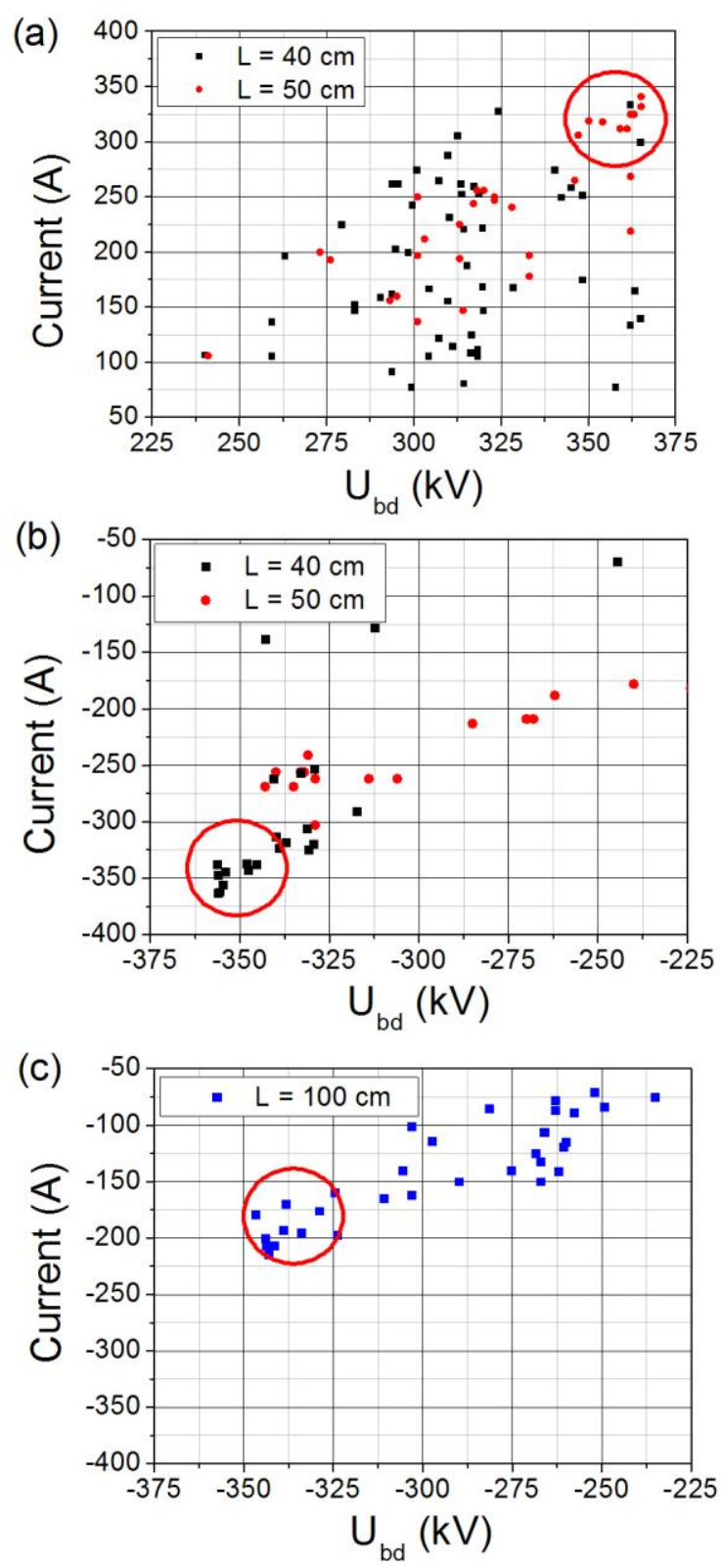

FIG 7. ( $\mathrm{I}_{\mathrm{max}}, \mathrm{U}_{\mathrm{bd}}$ ) characteristics for $\mathrm{L}=40$ and $50 \mathrm{~cm}$. (a): positive quadrant. (b): negative quadrant. (c) Negative quadrant of the $\left(\mathrm{I}_{\max }, \mathrm{U}_{\mathrm{bd}}\right)$ characteristic for $\mathrm{L}=100 \mathrm{~cm}$.

Experimental $\left(\mathrm{I}_{\max }, \mathrm{U}_{\mathrm{bd}}\right)$ characteristics for short gaps are presented in Figure 7. Data corresponds to the breakdown events occurring near the main four Tesla voltage peaks $\left(\mathrm{t}_{\mathrm{bd}}=16.8,21.6,26.4\right.$ and $\left.31.2 \mu \mathrm{s}\right)$. Because of insufficient statistics for the gap $\mathrm{L}=50 \mathrm{~cm}$, we joined data for both $\mathrm{L}=40$ and $50 \mathrm{~cm}$. The two panels show respectively the upper right $\left(\mathrm{I}_{\max }, \mathrm{U}_{\mathrm{bd}}>0\right)$ and lower left $\left(\mathrm{I}_{\max }, \mathrm{U}_{\mathrm{bd}}<0\right)$ quadrants of the whole $\left(\mathrm{I}_{\max }, \mathrm{U}_{\mathrm{bd}}\right)$ plane. The Figure 7(a) shows a significant scattering for the breakdowns occurring with a positive Tesla voltage, especially when $\mathrm{U}_{\mathrm{bd}}$ is moderately high $(<340 \mathrm{kV})$. In these conditions, the generated discharges are not reproducible. We relate this fluctuating behavior to the frequent occurrence of partially-guided discharges with short gaps. Indeed, as in this case the discharge path changes unpredictably from shot to shot, so does the total plasma resistance. The scattering becomes less important as $\mathrm{U}_{\mathrm{bd}}$ increases, enabling us to estimate the discharge operational resistance from the highlighted group in Figure $7(\mathrm{a})$. This gives $\mathrm{R}=1.2 \mathrm{k} \Omega$. As for the negative 
quadrant of the $\left(\mathrm{I}_{\max }, \mathrm{U}_{\mathrm{bd}}\right)$ characteristic, we observe no significant scattering of breakdown events (Figure 7(b)), which we cannot explain as of now. Still, to be coherent with the previous estimation, we again select the data with the highest voltage and peak current, undoubtedly resulting from full-fledged guided discharges (highlighted group in Figure 7(b)). This in turns yields an operational resistance $\mathrm{R}=1 \mathrm{k} \Omega$.

The study of longer gaps gives characteristics such as the one displayed in Figure 7(c) for $\mathrm{L}=100 \mathrm{~cm}$. Because the breakdown of long gaps occurs mostly when the Tesla voltage is negative, we concentrated on the discharges that took place around two significant negative peaks $\left(t_{\mathrm{bd}}=26.4\right.$ and $\left.36.1 \mu \mathrm{s}\right)$. Data scattering is not significant. Considering again the breakdown events at high $\mathrm{U}_{\mathrm{bd}}$ and $\mathrm{I}_{\max }$ (red group in Figure $7(\mathrm{c})$ ), we can estimate $\mathrm{R}=1.7 \mathrm{k} \Omega$. If we study the discharges occurring at lower voltage (around $230 \mathrm{kV}$ ), then we find an operational resistance $\mathrm{R}=3.3 \mathrm{k} \Omega$.

Measuring the guided discharge characteristics for each value of $\mathrm{L}$ enables us to plot the evolution of the operational resistance $\mathrm{R}$ with $\mathrm{L}$ (see Figure 8). To this purpose, we used the aforementioned method and only selected the data in the breakdown voltage range $-360 \mathrm{kV}<\mathrm{U}_{\mathrm{bd}}<-300 \mathrm{kV}$. Fitting this curve by a linear function gives a lineic resistance of $16 \Omega / \mathrm{cm}$.

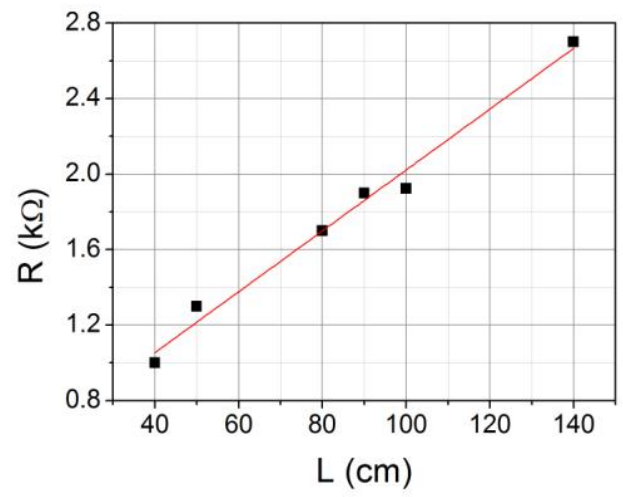

FIG. 8. Evolution of the operational resistance R with the gap length L (scatter plot) and linear fit (red solid line). Only breakdown occurring in the voltage range $-360 \mathrm{kV}<\mathrm{U}_{\mathrm{bd}}<-300 \mathrm{kV}$ were taken into account.

\section{DISCUSSION}

The discharge dynamics can be described by a simple modeling. Since the current flows for about $100 \mathrm{~ns}$ in the plasma, its origin lies in the discharge of the Tesla output capacitor $\mathrm{C}_{2}$, and not in the voltage oscillations of the Tesla coil, of which period is far larger $(\mathrm{T} \sim 10 \mu \mathrm{s})$. We can thus write:

$$
Q \approx I_{\max } \tau \approx C_{o u t} U_{b d}
$$

where $Q$ is the charge in the equivalent capacitor $C_{\text {out }}$ and $\tau$ corresponds to the full width at half maximum (FWHM) of the main current peak. A systematic investigation of the observed discharges for all gaps gives, for the Tesla coil output capacitor, a value $C_{\text {out }}=27 \pm 5 \mathrm{pF}$, which is lower than the measured value for $\mathrm{C}_{2}$ (49 $\mathrm{pF})$. We explain this discrepancy by leakages of the initial charge to the ground and through coronas. Indeed, partial corona discharges were already observed in the case of laser-guided discharges, as seen in [26]. More recently, streak images showing the development of a laser-guided discharge using a Tesla coil exhibited transient ionized channels appearing and disappearing with the generator oscillating voltage prior to the main discharge [23]. The feeding of charges in such transitory channels could also explain the charge loss observed in our experiments. Using this crude modeling, we can therefore estimate the discharge resistance as:

$$
\tau=2 R C_{\text {out }}
$$

which, for $\tau \approx 50 \mathrm{~ns}$ (corresponding to a gap length $\mathrm{L}=50 \mathrm{~cm}$ ) gives $\mathrm{R}=900 \Omega$, close to the measured operational resistance. Identifying the Tesla output voltage with the output capacitor voltage, we can also write its time evolution as:

$$
V_{2}(t)=U_{b d}-\frac{1}{C_{2}} \int_{t_{b d}}^{t} I_{t o t}\left(t^{\prime}\right) d t^{\prime}
$$


$I_{\text {tot }}$ being the total discharge current, including the leakages. Assuming that the measured current $I$ and the total current are related by $I=\frac{C_{\text {out }}}{C_{2}} I_{\text {tot }}$, one is then able to evaluate the gap voltage temporal evolution from the current measurements. However, estimating the plasma resistance at the time when the current is maximal is easier. Since the main current peak is approximately symmetric, this gives immediately:

$$
R_{\text {plasma }}\left(t=t\left(I_{\max }\right)\right)=\frac{U_{b d}}{2 I_{\max }}=\frac{R}{2} .
$$

Using this formula the guided discharge lineic resistance for the set of data in the breakdown voltage range $-360 \mathrm{kV}<\mathrm{U}_{\mathrm{bd}}<-300 \mathrm{kV}$ (see Figure 8 ) can then be estimated to $8 \Omega / \mathrm{cm}$.

The use of an AC generator to produce laser guided discharges leads to very specific experimental conditions when compared to the frequently used monopolar pulsed or DC sources. The dynamics for the discharge development is thought to be quite different in the case of an oscillating electric field. Previous study has proved that for centimeter-scale gaps in case of DC discharges, the initial plasma generated by filamentation has a too short lifetime (about $1 \mathrm{~ns}$ ) to cause breakdown by itself [27]. Instead, this plasma column undergoes a significant Joule heating in the presence of external electric field, causing the hydrodynamic expansion of the filament and in turn lowering the breakdown voltage in the resulting underdense gas channel. If we assume this scenario is also valid for longer gaps, we can explain the evolution of the breakdown probability with $\mathrm{t}_{\text {laser }}$ (see Figure 4). Indeed, if filamentation occurs when the gap electric field is strong, the resulting heating effect will be important, leading to the formation of a low-density channel. On the contrary, if the filamentation plasma is formed in a very weak external field, the heating effect will be almost inexistent. Still, even if it is low, breakdown probability in this case is not exactly zero. We even managed to score discharges when the laser was sent up to a few microseconds before the Tesla triggering, and this effect was also witnessed by other groups $[19,28,16]$. This could be explained by the fact that even in absence of external field, filamentation result in a low-density air channel over a microsecond timescale, as recently observed by Cheng et al. [29]. Thus, the external field only speeds up and enhances this hydrodynamic effect.

As for the discharge development taking place between $t_{\text {laser }}$ and $t_{b d}$, it has been shown to be dictated by the Tesla voltage oscillations [23]. In this paper, streak images displayed the progression of an ionized leader in the gap, which disappeared each time the Tesla voltage turned to 0 , and reappearing when it reached its local extremum. This behavior can explain why long gap breakdown can only be achieved by sending the laser at an early time. By doing so, the gap is exposed during a long time to the oscillating voltage, of which amplitude is rising. If the laser is sent later, the voltage has already passed the first half of the beating period, which means that the amplitude of the voltage peaks will be decreasing, effectively inhibiting the breakdown development.

\section{SUMMARY}

Laser guided discharges induced by laser filamentation in an oscillating electric field from a compact Tesla coil have been investigated. These voltage oscillations are characterized by a $9.6 \mu$ s period and maximum amplitude of $365 \mathrm{kV}$. Studies concentrated on the first half of the initial voltage beating period, characterized by an increasing amplitude for voltage extrema. The maximum gap length for self-breakdown has been measured to $\mathrm{L}_{\max }=36 \mathrm{~cm}$. With the laser filaments, we were able to achieve a $50 \%$ breakdown probability for $\mathrm{L}=140 \mathrm{~cm}$, and scored discharges for gaps up to $\mathrm{L}=180 \mathrm{~cm}$, corresponding to an increase of the discharge length by a factor 5 . With a $1 \mathrm{~m}$ gap, $10 \mathrm{~Hz}$ repetitive guided discharges were also demonstrated.

Sending the laser when the Tesla voltage was maximum created the most favorable conditions for discharges, with a noticeable dependence on the voltage polarity. Thus, more breakdowns were reported when the electric field direction was opposite to the laser propagation direction at the time of filament creation.

The onset of a guided discharge is also strongly correlated to the Tesla voltage local maxima, as breakdowns occur preferentially near such extrema. It is interesting to note that the delay between the laser shot and the breakdown is quite large, on the order of the period of the voltage oscillations ( $\mathrm{T}=9.6 \mu \mathrm{s})$. Long gaps require a longer time to close than short gaps, and can require up to $2 \mathrm{~T}$ before leading to breakdown.

Discharge current consists in strongly damped oscillations, with a main peak of which shape is close to a Gaussian curve. The surface of this peak remains approximately constant for different gaps, with short gaps resulting in a higher and narrower shape. Thus, a gap $\mathrm{L}=40 \mathrm{~cm}$ gives a current pulse of about $350 \mathrm{~A}$ for a $35 \mathrm{~ns}$ width while $\mathrm{L}=100 \mathrm{~cm}$ results in a $200 \mathrm{~A}, 60 \mathrm{~ns}$ peak. We were also able to estimate the plasma resistance at peak current. The evolution of this value with $L$ is close to linear, yielding a lineic resistance of $8 \Omega / \mathrm{cm}$. 


\section{Acknowledgements}

This work was supported by the French Direction Générale de 1'Armement (grant $\mathrm{n}^{\circ} 200795$ 091). The authors would like to thank Dr. Y. Liu, A. Dos Santos and Jean-Lou Charles for technical support.

\section{References}

1. S. L. Chin. S. A. Hosseini, W. Liu, Q. Luo, F. Théberge, N. Aközbek, A. Becker, V. P. Kandidov, O. G. Kosareva, H. Schroeder, Canadian Journal of Physics 83, 863 (2005).

2. A. Couairon and A. Mysyrowicz, Phys. Rep. 441, 47 (2007).

3. J. Kasparian and J.-P. Wolf, Optics Express 16, 466 (2008).

4. A. Houard, Y. Liu and A. Mysyrowicz, J. Phys.: Conf. Ser. 497, 012001 (2014).

5. H. Pepin, D. Comtois, F. Vidal, C. Y. Chien, A. Desparois, T. W. Johnston, J. C. Kieffer, B. La Fontaine, F. Martin, F. A. M. Rizk, C. Potvin, P. Couture, H. P. Mercure, A. Bondiou-Clergerie, P. Lalande and I.

Gallimberti, Phys. Plasmas 8, 2532 (2001).

6. M. Rodriguez, R. Sauerbrey, H. Wille, L. Wöste, T. Fujii, Y.-B. André, A. Mysyrowicz, L. Klingbeil, K. Rethmeier, W. Kalkner, J. Kasparian, E. Salmon, J. Yu, and J.-P. Wolf, Opt. Lett. 27, 772 (2002).

7. A. Houard, C. D’Amico, Y. Liu, Y. B. Andre, M. Franco, B. Prade, A. Mysyrowicz, E. Salmon P. Pierlot, L.-M. Cleon, Appl. Phys. Lett. 90, 171501 (2007).

8. B. Forestier, A. Houard, I. Revel, M. Durand, Y. B. André, B. Prade, A. Jarnac, J. Carbonnel, M. Le Nevé, J.

C. de Miscault, B. Esmiller, D. Chapuis and A. Mysyrowicz, AIP Advances 2, 012151 (2012).

9. X. M. Zhao, J.-C. Diels, A. Braun, X. Liu, D. Du, G. Korn, G. Mourou, and J. M. Elizondo, in Ultrafast Phenomena, Springer Series in Chemical Physics. New York: Springer-Verlag 60, 233 (1994).

10. J. Kasparian, M. Rodriguez, G. Méjean, J. Yu, E. Salmon, H. Wille, R. Bourayou, S. Frey, Y.-B. André, A. Mysyrowicz, R. Sauerbrey, J.-P. Wolf, L. Wöste, Science 301, 61 (2003).

11. B. Forestier, A. Houard, M. Durand, Y.B. André, B. Prade, J.Y. Dauvignac, F. Perret, Ch. Pichot, M. Pellet and A. Mysyrowicz, Appl. Phys. Lett. 96, 141111 (2010).

12. Y. Brelet, A. Houard, G. Point, B. Prade, L. Arantchouk, J. Carbonnel, Y.-B. Andre, M. Pellet, A.

Mysyrowicz, Appl. Phys. Lett. 101, 264106 (2012).

13. S. B. Leonov, A. A. Firsov, M. A. Shurupov, J. B. Michael, M. N. Shneider, R. B. Miles, and N. A. Popov, Phys. Plasmas 19, 123502 (2012).

14. G. Dufour, B. Fornet, F. Rogier, Int. J. of Aerodynamics 3, 122 (2013).

15. P. Rambo, J. Schwarz, M. Kimmel, A. Van Tassle, J. Urayama, D. Welch, D.d Rose, C. Thoma, R. E. Clark, C. Miller, W. R. Zimmerman, T. A. Pitts, M. R. Laine, B. Hautzenroeder, and B. Atherton, Sandia National Laboratories, Report number SAND2012-8105 (2012)

16. L. Arantchouk, A. Houard, Y. Brelet, J. Carbonnel, J. Larour, Y-B André and A. Mysyrowicz, Appl. Phys. Lett. 102, 163502 (2013).

17. L. Arantchouk, G. Point, Y. Brelet, J. Larour, J. Carbonnel, Y.-B. André, A. Mysyrowicz and A. Houard, Appl. Phys. Lett. 104, 103506 (2014).

18. D. Comtois, H. Pépin, F. Vidal, F. A. M. Rizk, C.-Y. Chien, T. W. Johnston, J.-C. Kieffer, B. La Fontaine, F. Martin, C. Potvin, P. Couture, H. P. Mercure, A. Bondiou-Clergerie, P. Lalande, and I. Gallimberti, IEEE Trans. on Plasma Science 31, 377, (2003).

19. R. Ackermann, G. Méchain, G. Méjean, R. Bourayou, M. Rodriguez, K. Stelmaszczyk, J. Kasparian, J. Yu, E. Salmon, S. Tzortzakis, Y.-B. André, J.-F. Bourrillon, L. Tamin, J.-P. Cascelli, C. Campo, C. Davoise, A. Mysyrowicz, R. Sauerbrey, L. Wöste, J.-P. Wolf, Appl. Phys. B 82, 561 (2006).

20. F. Gordon, A. Ting, R. F. Hubbard, E. Briscoe, C. Manka, S. P. Slinker, A. P. Baronavski, H. D. Ladouceur, P. W. Grounds and P. G. Girardi, Physics of Plasma 10, 4530 (2003).

21. Y. Brelet, A. Houard, L. Arantchouk, B. Forestier, Y. Liu, B. Prade, J. Carbonnel, Y.-B. Andre and A. Mysyrowicz, Appl. Phys. Lett. 100, 181112 (2012).

22. M. Henriksson, J.-F. Daigle, F. Théberge, M. Châteauneuf, and J. Dubois, Opt. Express 20, 12721 (2012).

23. J.-F. Daigle, F. Théberge, P. Lassonde, J.-C. Kieffer, T. Fujii, J. Fortin, M. Châteauneuf and J. Dubois, Appl. Phys. Lett. 103, 184101 (2013).

24. G. Point, Y. Brelet, A. Houard, V. Jukna, C. Milián, J. Carbonnel, Y. Liu, A. Couairon, and A. Mysyrowicz, Phys. Rev. Lett. 112, 223902 (2014).

25. R.G. Medhurst, Wireless Eng. 24, 35-43 (1947).

26. T. Fujii, M. Miki, N. Goto, A. Zhidkov, T. Fukuchi, Y. Oishi and K. Nemoto, Physics of Plasmas 15, 013107 (2008).

27. S. Tzortzakis, B. Prade, M. Franco, A. Mysyrowicz, S. Hüller and P. Mora, Phys. Rev. E 64, 057401 (2001). 28. B. La Fontaine, F. Vidal, D. Comtois, C.-Y. Chien, A. Desparois, T. W. Johnston, J.-C. Kieffer, H. P. Mercure, H. Pepin, and F. A. M. Rizk, IEEE Trans. Plasma Sci. 27, 688 (1999). 
29. Y.-H. Cheng, J. K. Wahlstrand, N. Jhajj and H. M. Milchberg, Opt. Express 21, 4740 (2013). 